УДК: 004.75

\title{
Cloud computing for virtual testbed
}

\author{
A. B. Degtyarev ${ }^{1, a}$, Myo Min Swe ${ }^{2, b}$, Wunna Kyaw ${ }^{2, c}$ \\ ${ }^{1}$ St.Petersburg State University, Saint-Petersburg, Russia \\ ${ }^{2}$ St.Petersburg State Marine Technical University, 3 Lotsmanskaya Str., St.Petersburg, 190008 Russia \\ E-mail: adeg@csa.ru, beltson@gmail.com, cwna.ru.pol@gmail.com
}

Received October 1, 2014

Nowadays cloud computing is an important topic in the field of information technology and computer system. Several companies and educational institutes have deployed cloud infrastructures to overcome their problems such as easy data access, software updates with minimal cost, large or unlimited storage, efficient cost factor, backup storage and disaster recovery, and some other benefits if compare with the traditional network infrastructures. The paper present the study of cloud computing technology for marine environmental data and processing. Cloud computing of marine environment information is proposed for the integration and sharing of marine information resources. It is highly desirable to perform empirical requiring numerous interactions with web servers and transfers of very large archival data files without affecting operational information system infrastructure. In this paper, we consider the cloud computing for virtual testbed to minimize the cost. That is related to real time infrastructure.

Keywords: cloud computing, cloud storage, modeling of marine environments

\section{Облачные вычисления для виртуального полигона}

\author{
А. Б. Дегтярев ${ }^{1}$, Мьё Мин Све ${ }^{2}$, Вунна Киав $^{2}$ \\ ${ }^{1}$ Санкт-Петербургский государственный университет, Россия, 198504, г. Санкт-Петербург, Петергоф, \\ Университетский просп., д. 35 \\ ${ }^{2}$ Санкт-Петербургский государственный морской технический университет, Россия, 190008, г. Санкт- \\ Петербург, ул. Лоиманская, д. 3
}

В настоящее время облачные вычисления являются важной и актуальной темой в ИТ. Многие компании и учебные заведения развертывают облачные инфраструктуры, чтобы преодолеть свои проблемы, такие как легкость доступа к данным, обновление программного обеспечения с минимальными затратами, возможности неограниченного хранения данных и ряд других преимуществ по сравнению с традиционными сетевыми инфраструктурами. В работе рассматривается применение технологий облачных вычислений при моделировании морской среды и обработке данных. В данном случае облачные вычисления предлагается для интеграции и совместного использования морских информационных ресурсов. В статье облачные вычисления рассматриваются как средство снижения затрат при организации виртуального полигона в морских исследованиях.

Ключевые слова: облачные вычисления, облачное хранение данных, моделирование морской среды Citation: Computer Research and Modeling, 2015, vol. 7, no. 3, pp. 753-758. 


\section{Introduction}

Cloud computing is very new concept of computing. It has been thought and realized as a future generation of computing with the promise of revolutionizing the ICT services by transforming computing into a ubiquitous utility. The rapid change in technology, frequent updates in users' demand and associative high cost in managing users' demand and available technology have been a big challenges in the history of computing. The disparity in the cost of hardware and software has made the big obstacles in computing. Buying the required infrastructures, operating it and upgrading it are the great issues in computing field. The users' community was worried and expecting something miracle to overcome these challenges. They were expecting the computing facilities and required resources should be available on demand like other utility facilities. Their expectations have been addressed by cloud computing where computing is treated as a utility and computing facilities would be provided on demand. The cloud computing is the computing in cloud where as the cloud refers to virtual servers; distributed hosting, and shared resources available over Internet. The users can access the cloud for available service through the web browser and Internet connectivity. In cloud computing, software, hardware and network are the main actors. The collective effort of these actors make the cloud computing. We can also visualize the cloud as a cluster of computers which are based upon distributed system that provide services in real time over a network and these characteristics make the possibility of using cloud computing in ICT based system. ICT based system needs to provide required services to required users on the required time. There are many ICT based systems using in different organizations.

\section{Basic characteristics}

Cloud computing is the collection of scalable, virtualized resources, which is capable of hosting application and providing required services to the users and can charge as per the uses like utility. A could computing has also been defined by Ian Foster et al, as a distributed computing paradigm that is driven by economies of scale, in which pool of abstracted, virtualized, dynamically-scalable, managed computing power, storage, platforms and services are delivered on demand to external customers over the Internet [Grossman, 2009]. It is a model for enabling convenient, on- demand network access to a shared pool of configurable computing resources such as networks, servers, storage, application that can be rapidly provisioned and released with minimal management effort or service provider interaction [ISACA ..., 2014].

The main goal of cloud computing is to provide ICT services with shared infrastructure and the collection of many systems. In cloud computing every facility is provided in term of service. It provides infrastructure as a service, software as a service, platform as a service, network as a service, and data storage as a service. The main philosophy of cloud computing is to provide every required things as a service. In order to be clearer, the services in the cloud can be shown in term of layer structure.

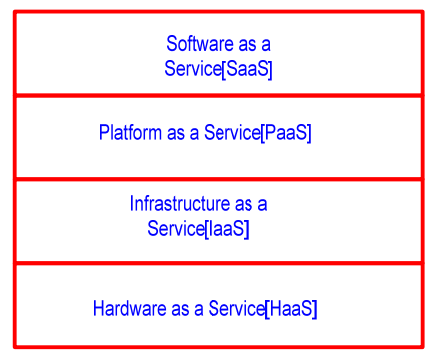

Fig. 1. Layers in cloud computing

The Figure 1 depicts the services in terms of the layers. The foundation or lowest layer is HaaS(Hardware as a service) that provides every required hardware. The layer just above this is IaaS (Infrastructure as a service) that takes the care of required infrastructure. Similarly, we have two top 
most layer i.e. PaaS(Platform as a service) and SaaS(Software as a service) which provide the required platform and required software to the users. In general, the bottom three layers are used by developer whereas the top layer is used by user communities. The use of such services by different users is given in Section 2.1 with UML use case diagram.

\section{Cloud computing technology}

Cloud computing has the set of various supporting technologies. A single technology is not sufficient to provide smooth functioning of cloud computing. In cloud computing, it is assumed that software and hardware services are essentially stored in the web servers, the cloud rather than spread over the single computers connected in Internet [Aymerich et al., 2008]. The advent and maturity of virtualization technology enables compute clouds which make demand for cloud that can store, we call this as storage cloud. The storage cloud and compute cloud together make cloud infrastructure as given in layer 2 of above Figure 1. This cloud infrastructure makes the possibility of platforms and finally it supports for the application in the top layer of above figure. More than one cloud makes the cloud aggregators. It needs the cooperation of many available technologies. They are given in Figure 2.

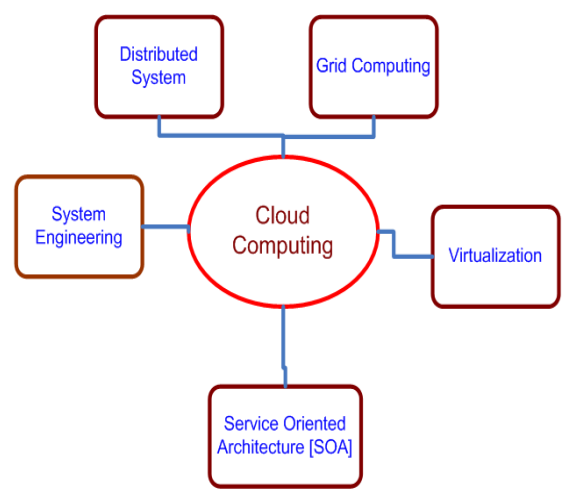

Fig. 2. Technology in Cloud Computing

In Figure 2, it has shown the required technologies in cloud computing. Distributed system is one of the technologies to provide the support in cloud computing because the nature of cloud is distributed and it needs a special kind of collaboration and cooperation among the computing nodes. Grid computing is another one which is required to solve a common problem with the help of clustering computing nodes in clouds. There are still many similarities between grid and cloud computing. Virtualization can be used in cloud to virtualize all the physical resources. Virtualization is a technology that combines or divides computing resources to give the environment for one or many operating systems using hardware and software partitioning. Service oriented architecture (SOA), which is a kind of software architectures, is required to provide all the facilities in terms of services. The main philosophy of cloud computing is based upon the Service Request and Service Provide. The components in SOA communicate each other with standard SOAP (Simple Object Access Protocol) which is mostly written in XML code that makes the possibility of interacting among the heterogeneous environment. This is the reason of using SOA in cloud computing. The last but not the least is system engineering. System engineering and its approach is the basic foundation for cloud computing. Cloud has to be thought in terms of system and it has to go through system development life cycle. All phases in system development life cycle is crucial in cloud computing.

\section{Types of cloud and features}

In general, cloud is classified into two types. They are as: private cloud and public cloud. The classification is based upon the degree of authentication and authorization in cloud resources. The re- 
sources in public cloud can be access by everyone where as the resources in private cloud cannot be accessed by everyone. There is a restriction. Mostly, the big organization makes the cloud private for their internal use. Sometimes there is a need of controlling the access of the resources in cloud and at the same time it is required to give access to limited users outside the organization, which is possible with another type of cloud i.e. hybrid cloud. It has the features of both private as well as public cloud. It is a composition of two or more clouds such as private cloud, public cloud and sometimes community cloud that remain unique entities but are bound together by standards technology that enables data and application portability. Amazon's EC2, S3 are the examples of public or hosted cloud and Google uses GFS, MapReduce and BigTable as private cloud.

The popularity of cloud computing is because of the available features in cloud computing. There are many identified features but we reveal only prime features that are pertinent to all system.

Scalability: It is one of the features in cloud computing in which the use of multiple resources can be expanded whenever it is needed and can be reduced if it is not needed. Both expansion and reduction of resources can be done without paying extra money or concerning of extra infrastructure. Considering the constrained capacity, cloud computing offers increased flexibility on scalability for evolving ICT needs.

Low Risk: In cloud computing, there is nothing to purchase except the required services. It is also possible to cancel the services if it is not needed. All the services are kept in the cloud with proper testing mechanism. These features reduce the risk of buying the product and unreliability of any product.

Reliability and Survivability: Virtualization is one of the technologies that are used in cloud computing. As we know, virtualization increases the reliability, increases the survivability and also reduces the downtime.

Availability: Cloud computing provides maximum availability on the system because of multiple cloud. This means if one cloud goes down then another takes the charge immediately. Fault tolerance capability is very high in cloud computing. Cloud service providers have enough infrastructure and bandwidth to accommodate business needs for high speed access, storage, computing and applications. Since the service provider use the features such as load balancing the systems are not overloaded and not service delayed.

Low Cost: "Pay as Work" philosophy of cloud computing makes the cost very low. If servers are not requires, we can turn it off and if it is required then turn it on again. There is no need to buy any infrastructure or pay for it in advance and also no capital expenses are required.

Ubiquitous Network Cloud can provide the capabilities over the network and accessed through standard mechanisms that promote use by heterogeneous thin or thick client platforms such as cell phone, tablet, notebook, and I-Phone etc.

\section{Prospective area and future challenges}

Despite of huge welcome by many communities, there are still many doubts to be removed, questions to be solved and issues to be addressed in cloud computing. It has given the opportunity for students, researchers and research-based organizations to conduct respective researches and find the concrete solutions. We identify the following prospective areas in which researches are required.

Cloud security: Security is one of the prime issues in cloud computing. The cloud users are still reluctant to share or give their critical data to cloud provider. Still there is no convincing security mechanism in cloud computing. Perimeter security and contain (data) security could be the area for the research.

Cloud computing in ubiquitous computing: There are so many ubiquitous devices now days. People use their cell phone, notebook, I-phone and other devices for their daily activities. Still there are so many complain such as low latency rate, unreliability, unavailability of services, bandwidth congestion etc. A research can be done to solve these issues. Along with these, the issues of pervasive software can also be solved using cloud computing. 
Interoperability among cloud provider (Data Lock-In): At present, there are many cloud service providers and they have standard APIs to interact each other but tomorrow there may be many cloud service providers. One user may use more than one cloud service providers or one cloud service provider may have many different types of users. Still there are much works required for the standardization in cloud's APIs. Hence there is a need of details interoperability among them.

Cloud computing in traffic management: Current GPS system of traffic management can be replaced by cloud computing based traffic management. A good comparison can be made between existing GPS based traffic management and proposed cloud-based traffic management.

Cloud computing in e-business: Electronic business has blanketed entire world. People around the world use maximum e-business for purchasing and their demand of using it is keep on changing. The service provider has a very tough time to update their system to meet the people's demand in regular basis. A significant research can be done in using cloud computing in electronic business to address all these problems.

Automated Efficient Backup and Recovery in Cloud computing: Backup the critical data to the cloud and recovery from it whenever it needs are one of the activities of cloud. Efficient recovery plan in case of disaster is also one of the areas in which researches can be done.

Cloud based Software Testing: Software testing has been very sensitive task in software development process especially in embedded software testing. Rapid change in business process, increasing complexity, shorter time to market have made software testing more complex , time consuming and expensive. The cost of finding and removing bugs has become exponential and there is a need to invest huge amount in infrastructure to set up machines for analyzing source code, developing test cases, running the tests etc. Hence, we can analyze and compare between traditional-based software testing and cloud-based software testing with the resources provided by the cloud service providers such as simple storage solution(S3), elastic computing cloud(EC2) etc.

Quick response in resource scaling up and down: Scalability is one of the features of cloud computing. Sometimes the system in the cloud service provider does not response quickly. A research for quick response as per the load balance can be done without affecting service level agreement (SLA).

In cloud computing there are three main models, i.e. computation, storage and network model. These models do require significant research to make them more effective than today [Armbrust et al., 2009].

Along with above mentioned areas, a special thought can be given in each service of cloud computing. There are some unidentified problems in each service. These hidden problems can be identified and proper solution can be suggested.

\section{Conclusion and future work}

Virtual testbed can be deployed within cloud environment to minimize the implementation cost and achieve more benefits during communication. The cloud computing platform is a most reliable and cost less solution for real time infrastructures, including applications oriented to consumers, applications supporting the enterprise, and applications for large scale science. This trend is expected to continue for the foreseeable future. However, in many ways research in cloud computing is still immature. There is limited understanding of basic issues, such as exploiting data locality, load balancing, and identifying nodes and collections of nodes that are damaging the overall performance of an application. We also exposed potential areas of cloud computing in which interested researcher can contribute their work to make cloud computing more better in coming days.

\section{References}

Aymerich Maria Francesco, Fenu Gianni, Surcis Simone. An Approach to Cloud Computing Network // IEEE-2008. 
Armbrust Michael et al. Above the Clouds: A Berkeley View of Cloud Computing // Technical Report No. UCB/EECS-2009-28. — http://www. eecs.berkeley.edu/Pubs/TechRpts/2009/EECS-200928.html, Feb, 2009.

Aronson Jesse S., "Making IT a Positive Force in Environment Change", IEEE-2008.

Bianco, Phil., Kotermanski, Rick., Merson, Paulo, "Evaluating a Service-Oriented Architectures", Technical Report, SEI, Carnegie Mellon University, September-2007.

Estevez Elsa, Janowski Tomasz, "Building a Dependable Messaging Infrastructure for Electronic Government". UNU/IIST Report No 368. April 2007.

Foster Ian, Zhao Yong, Raicu Ioan, Lu Shiyong, "Cloud Computing and Grid Computing 360-Degree Compared", IEEE.

Greenberg, Albert, Lahiri, Parantap, Maltz, David A., Patel, Parveen, Sengupta, Sudipa, "Towards A Next Generation Data Center Architecture: Scalability and Commodigitization", ACM-2008.

Grossman Robert L. The case of cloud computing // IEEE-2009.

Heddaya, Abdelsalam, Helal Abdelsalam Helal, "Reliability, Availability, Dependability and Performability: A User Centered View", Boston University, Dec 04,1996.

Heek Richard, "Implementing and Managing E-Government", Vistaar Publication- 2006.

ISACA, "Cloud Computing: Business Benefits with Security, Governance and Assurance Perspectives," www.isaca.org

Janssen Marijn, Cressworld Anthony, "Enterprise Architecture Integration in E-Government", 38th Hawaii International Conference on System Sciences- IEEE- 2005.

Kencl, Lucas, Schwarzer, Christian, "Traffic Adaptive Packet Filtering of Denial of Service Attack", IEEE- 2006.

Leavitt Neil, "Is Cloud Computing Really Ready for Prime Time?" IEEE-2009.

Lin, Mei, Yongsen, Xu, "An Adaptive Dependability Model of Component-Based Software", ACM SIGSOFT, Software Engineering Notes Volume 28 No 2, March 2003.

Murugesan San, "Harnessing Green IT: Principles and Practice.", IEEE-2008.

Youseff Lamia, Butrico Maria, Da Silva Dilma, "Towards a Unified Ontology of Cloud Computing”Grid Computing Environments Workshop 2008, GCE08'. 